\section{RMD Open}

Rheumatic \&

Musculoskeletal Diseases
To cite: Fleischmann R, Alam J, Arora V, et al. Safety and efficacy of baricitinib in elderly patients with rheumatoid arthritis. RMD Open 2017;3:e000546. doi:10.1136/ rmdopen-2017-000546

- Prepublication history and additional material for this paper are available online. To view please visit the journal (http://dx doi.org/10.1136/bmjopen-2016000546).

This manuscript is based on work presented at the 2016 ACR/ARHP Annual Meeting: Fleischmann R, Alam J, Arora V, Bradley JD, Schlichting DE, Muram D. Safety and Efficacy of Baricitinib in Elderly Patients with Moderate to Severe Rheumatoid Arthritis [abstract]. Arthritis Rheumatol 2016;68(suppl 10).

Received 1 August 2017 Revised 5 September 2017 Accepted 15 September 2017

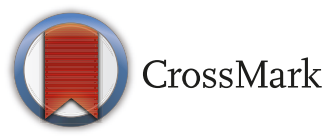

'Department of Medicine, University of Texas Southwestern Medical Center, Dallas, TX ${ }^{2}$ Eli Lilly and Company, Indianapolis, Indiana, USA ${ }^{3}$ Division of Rheumatology, Department of Medicine 3, Medical University of Vienna, Vienna, Austria

Correspondence to Dr Roy Fleischmann; rfleischmann@arthdocs.com

\title{
Safety and efficacy of baricitinib in elderly patients with rheumatoid arthritis
}

\author{
Roy Fleischmann, ${ }^{1}$ Jahangir Alam, ${ }^{2}$ Vipin Arora, ${ }^{2}$ John Bradley, ${ }^{2}$ \\ Douglas E Schlichting, ${ }^{2}$ David Muram, ${ }^{2}$ Josef $S$ Smolen ${ }^{3}$
}

\section{INTRODUCTION}

Rheumatoid arthritis (RA) can begin at any age, but the prevalence increases with age. Active disease usually persists for years; many patients have initial symptoms after age $60 .^{12}$ Elderly patients with RA often have comorbid diseases managed with multiple concomitant medications with the potential for changes in drug pharmacokinetics and pharmacodynamics, which complicate therapeutic decisions. ${ }^{3}$ Moreover, there is a perception that medications may be less effective than in younger individuals and adverse effects more common and severe. ${ }^{45}$ One report suggests an increased risk in elderly patients for adverse events (AE) leading to discontinuation of biologic disease-modifying antirheumatic drugs (bDMARD) in the treatment of RA, while other reports have not seen these effects. ${ }^{45}$ An analysis of Medicare beneficiaries with RA suggested that older patients were less likely to receive conventional synthetic disease-modifying antirheumatic drugs (csDMARD) and therefore may not receive optimal treatment. ${ }^{6}$ Other reports have shown that responsiveness of elderly patients with RA to methotrexate (MTX) or tumour necrosis factor (TNF) inhibitors+MTX was similar to that observed in younger patients. ${ }^{3}$

Baricitinib is an oral selective inhibitor of Janus kinase (JAK) 1 and JAK2 ${ }^{7}$ and has been shown to improve RA signs and symptoms in phase III controlled studies in patients with active RA despite treatment with TNF inhibitors (RA-BEACON), csDMARDs (RA-BUILD) and MTX (RA-BEAM), and in csDMARDnaive patients (RA-BEGIN).$^{8-11}$ Here, we describe the safety and efficacy of baricitinib in elderly patients (aged $\geq 65$ years) compared with patients aged $<50$, and $\geq 50$ and $<65$ years, from pooled data of the two studies of patients with inadequate response (IR) to csDMARDs,

\section{Key messages}

What is already known about this subject?

- Elderly patients with rheumatoid arthritis (RA) often have comorbid diseases managed with multiple concomitant medications with the potential for changes in drug pharmacokinetics and pharmacodynamics, which complicate therapeutic decisions.

- There may be an increased risk in elderly patients for institution of biologic disease-modifying antirheumatic drugs in the treatment of RA.

What does this study add?

- We have demonstrated similar efficacy of baricitinib in elderly and younger patients and incidence of serious adverse events (AE) or withdrawal due to AEs in baricitinib-treated patients that were similar to age-matched placebo-treated patients.

How might this impact on clinical practice?

- Age is not a contraindication to the institution of targeted therapies, including baricitinib; given their comorbidities and changed pharmacodynamics, elderly patients with RA should be followed carefully to be sure that there is a reasonable risk:benefit profile of baricitinib in individual patients.

RA-BUILD (NCT01721057) and RA-BEAM (NCT01710358).

\section{METHODS}

\section{Study design and patients}

The study design and patient inclusion/ exclusion criteria for each study have been described previously. ${ }^{9}{ }^{10}$ Briefly, patients with $\geq 6 / 66$ swollen and $\geq 6 / 68$ tender joints and no prior bDMARD use were eligible. The presence of comorbidities that, in the opinion of the investigator, could constitute a risk when taking investigational product or could interfere with the interpretation of data 
was exclusionary. In the 24-week RA-BUILD study, 684 csDMARD-IR patients with active RA were randomised 1:1:1 to receive oral placebo or $2 \mathrm{mg}$ or $4 \mathrm{mg}$ baricitinib once daily. In the 52-week RA-BEAM study, 1305 MTX-IR patients with active RA were randomised 3:3:2 to receive oral placebo once daily, $4 \mathrm{mg}$ baricitinib once daily, or subcutaneous injection of adalimumab every 2 weeks. Patients in both studies continued background csDMARD (including MTX) therapy.

The primary endpoint in the studies was the American College of Rheumatology 20\% (ACR20) response rate at week 12. Key secondary endpoints were ACR50/70, improvement from baseline in the Disease Activity Score based on 28 joints (DAS28)-hsCRP (high-sensitivity C-reactive protein) and HAQ-DI (Health Assessment Questionnaire-Disability Index), as well as the percentage of patients who achieved low disease activity (LDA) or remission based on the Simplified Disease Activity Index (SDAI) and the Clinical Disease Activity Index (CDAI). The studies were designed by the sponsor (Eli Lilly and Company) in consultation with an academic advisory board of the non-Lilly authors and Incyte. The studies were conducted in accordance with the ethical principles of the Declaration of Helsinki and Good Clinical Practice guidelines. All patients provided written informed consent.

\section{Statistical analysis}

This post hoc analysis combined data from both trials providing overall samples for placebo $(\mathrm{n}=716)$ and baricitinib $4 \mathrm{mg}(\mathrm{n}=714)$. Summary statistics are presented for demographic, efficacy and safety data for patients aged

Table 1 Baseline demographic and disease characteristics

\begin{tabular}{|c|c|c|c|c|c|c|}
\hline & \multicolumn{2}{|l|}{$<50$ years } & \multicolumn{2}{|c|}{$\geq 50$ and $<65$ years } & \multicolumn{2}{|l|}{$\geq 65$ years } \\
\hline & $\begin{array}{l}\text { Placebo } \\
(\mathrm{n}=254)\end{array}$ & $\begin{array}{l}\text { Baricitinib } \\
4 \mathrm{mg}(\mathrm{n}=259)\end{array}$ & $\begin{array}{l}\text { Placebo } \\
(\mathrm{n}=349)\end{array}$ & $\begin{array}{l}\text { Baricitinib } \\
4 \mathrm{mg}(\mathrm{n}=319)\end{array}$ & $\begin{array}{l}\text { Placebo } \\
(n=113)\end{array}$ & $\begin{array}{l}\text { Baricitinib } \\
4 \mathrm{mg} \\
(\mathrm{n}=136)\end{array}$ \\
\hline Age & $39.7(7.5)$ & $40.0(7.2)$ & $56.9(4.3)$ & $56.5(4.0)$ & $69.5(4.1)$ & $69.6(4.2)$ \\
\hline Female, n (\%) & $218(85.8)$ & $214(82.6)$ & $263(75.4)$ & $246(77.1)$ & $90(79.6)$ & $102(75.0)$ \\
\hline $\begin{array}{l}\text { Central and South America, Mexico, } \\
\mathrm{n}(\%)\end{array}$ & $72(28.3)$ & $72(27.8)$ & $76(21.8)$ & $72(22.6)$ & $21(18.6)$ & $28(20.6)$ \\
\hline Eastern Europe, n (\%) & $42(16.5)$ & 37 (14.3) & $58(16.6)$ & $58(18.2)$ & $23(20.4)$ & $25(18.4)$ \\
\hline Western Europe, n (\%) & $12(4.7)$ & $13(5.0)$ & $27(7.7)$ & $24(7.5)$ & 15 (13.3) & $16(11.8)$ \\
\hline$<1$ year, $\mathrm{n}(\%)$ & $46(18.1)$ & $41(15.9)$ & $49(14.0)$ & $50(15.7)$ & $10(8.9)$ & $22(16.2)$ \\
\hline$\geq 1$ to <5years, n (\%) & $94(37.0)$ & $101(37.1)$ & $111(31.8)$ & $102(32.0)$ & $29(25.9)$ & $30(22.1)$ \\
\hline$\geq 5$ to <10years, $n(\%)$ & $62(24.4)$ & $63(24.4)$ & $79(22.6)$ & $67(21.0)$ & 25 (22.3) & $36(26.5)$ \\
\hline z10years, n (\%) & $52(20.5)$ & $53(20.5)$ & $110(31.5)$ & $100(31.3)$ & $48(42.9)$ & $48(35.3)$ \\
\hline ACPA positive, n (\%) & $214(84.3)$ & $208(80.3)$ & $288(82.5)$ & $269(84.3)$ & $94(83.2)$ & $113(83.1)$ \\
\hline RF positive, n (\%) & $223(87.8)$ & $223(86.1)$ & $304(87.1)$ & $272(85.3)$ & $95(84.1)$ & $117(86.0)$ \\
\hline Swollen joint count of 66 & $14.0(8.5)$ & $14.6(8.2)$ & $15.1(9.6)$ & $14.6(7.8)$ & $15.1(7.4)$ & $14.2(7.4)$ \\
\hline Tender joint count of 68 & $22.8(12.6)$ & $23.9(13.3)$ & $23.9(14.7)$ & $23.8(13.4)$ & $24.7(14.7)$ & $22.9(13.1)$ \\
\hline hsCRP, mg/L & $18.1(18.7)$ & $19.6(20.9)$ & $20.0(20.7)$ & $20.3(20.8)$ & $18.1(25.2)$ & $18.2(21.2)$ \\
\hline
\end{tabular}

Data are mean (SD) unless otherwise noted.

${ }^{*}$ Time since diagnosis.

ACPA, anti-citrullinated peptide antibody; CDAI, Clinical Disease Activity Index; DAS28, Disease Activity Score based on 28 joints; ESR, erythrocyte sedimentation rate; HAQ-DI, Health Assessment Questionnaire-Disability Index; hsCRP, high-sensitivity C-reactive protein; RA, rheumatoid arthritis; RF, rheumatoid factor; SDAI, Simple Disease Activity Index. 
A

ACR 20/50/70 at Week 12

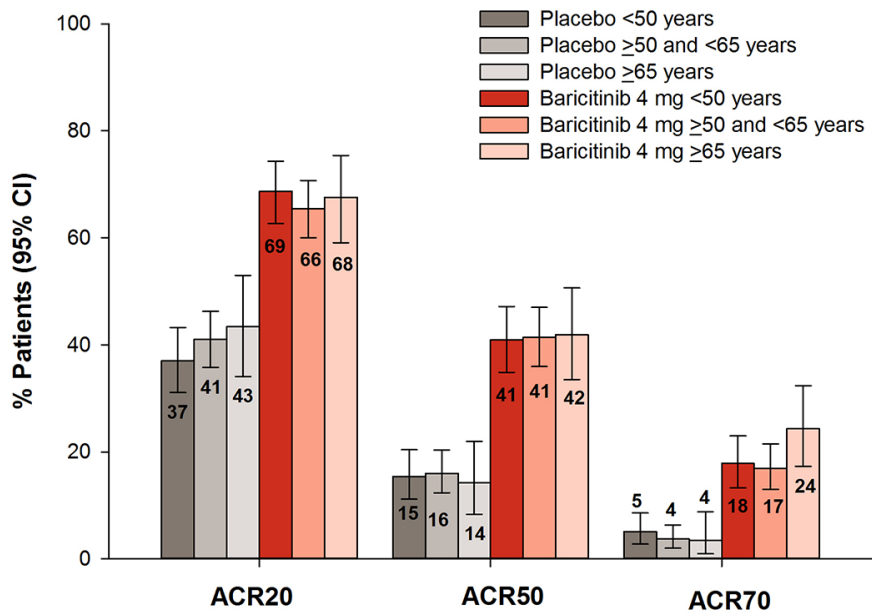

C CDAI Low Disease Activity/Remission at Week 24

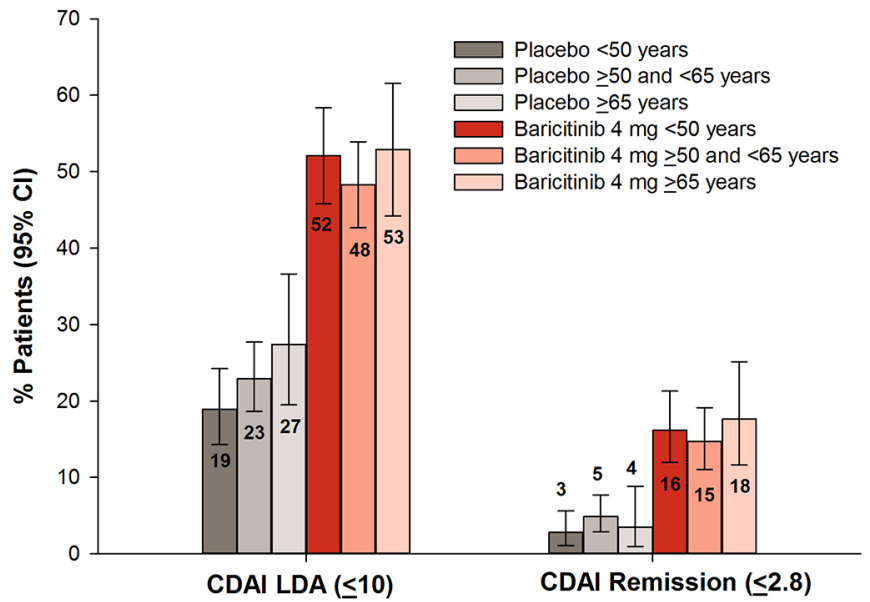

B

ACR 20/50/70 at Week 24

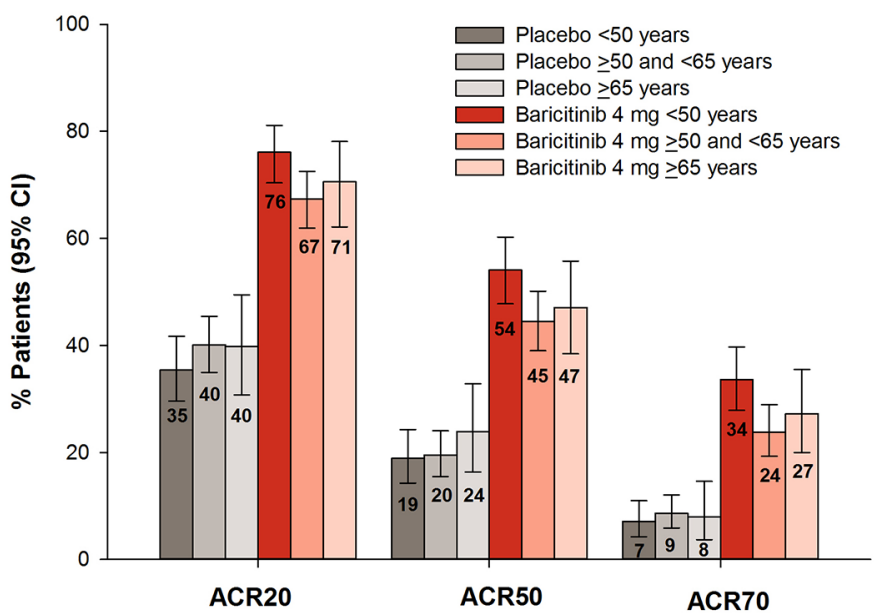

DDAI Low Disease Activity/Remission at Week 24

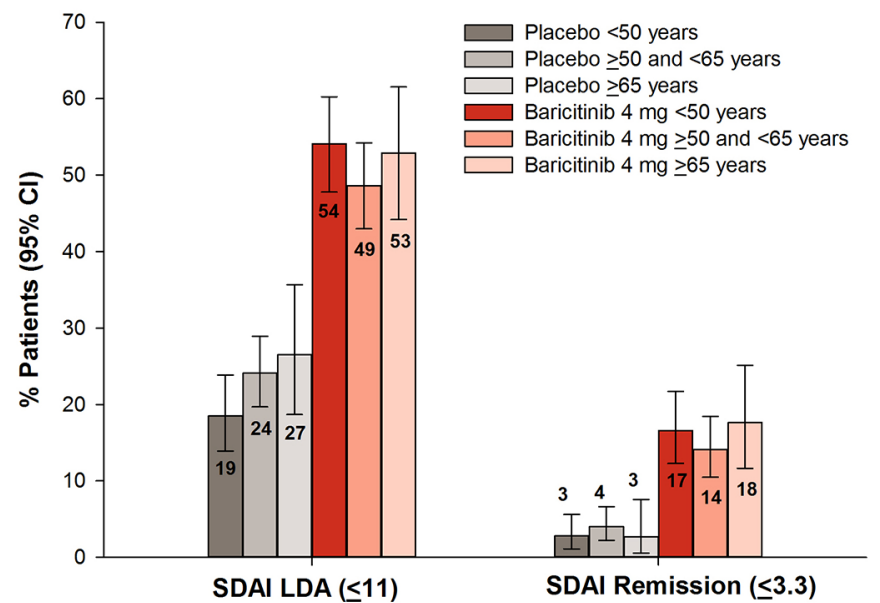

Figure 1 Efficacy outcomes in patients aged $\geq 65$ years versus younger patients: $A C R$ outcomes at $(A)$ week 12 and $(B)$ week 24. Patients achieving low disease activity and remission at week 24 based on (C) CDAI and (D) SDAI. ACR20/50/70, American College of Rheumatology 20\%/50\%/70\%; CDAI, Clinical Disease Activity Index; LDA, low disease activity; SDAI, Simplified Disease Activity Index.

$<50, \geq 50$ and $<65$, and $\geq 65$ years. For categorical efficacy outcomes, non-responder imputation was used in analyses for patients who received rescue therapy or discontinued from the study or study treatment. For safety outcomes, data after discontinuation or rescue were censored from the analysis. To detect significant interactions between treatment and subgroups, the following logistic regression model was used: treatment group+subgroup+treatment-by-subgroup+study. Within a subgroup, OR and $95 \%$ CIs were from a logistic regression model: treatment group+study.

\section{RESULTS}

Pooled data from both studies included 1989 patients, counting patients randomised to baricitinib $2 \mathrm{mg}$ in RA-BUILD $(n=229)$ and adalimumab in RA-BEAM $(n=330)$; this analysis only included patients in the placebo $(n=716)$ and baricitinib $4 \mathrm{mg}(\mathrm{n}=714)$ arms. Of these, $17 \%(n=249)$ randomised to placebo $(n=113)$ or baricitinib $4 \mathrm{mg}(\mathrm{n}=136)$ were aged $\geq 65$ years. Baseline demographic and disease characteristics by age group are presented in table 1 .

Efficacy was similar in patients regardless of age group. ACR20 response rates at week 12 for placebo were $37 \%$, $41 \%$ and $43 \%$ for $<50, \geq 50$ and $<65$, and $\geq 65$ age groups, respectively, and baricitinib $4 \mathrm{mg}$ percentages were $69 \%$, $66 \%$ and $68 \%$; compared with week 12 , percentages at week 24 were similar for ACR20 response and for achievement of ACR50/70 (figure 1A,B). The proportion of patients who achieved remission or LDA based on the CDAI or SDAI was similar in placebo-treated and baricitinib-treated patients across the three age groups, respectively (figure $1 \mathrm{C}, \mathrm{D}$ ).

AEs, serious adverse events (SAE) and discontinuations due to AEs occurred more frequently in elderly patients compared with patients aged $<50$, or $\geq 50$ and $<65$ years, 
Table 2 Safety at week 24

\begin{tabular}{|c|c|c|c|c|c|c|}
\hline & \multicolumn{2}{|l|}{$<50$ years } & \multicolumn{2}{|c|}{$\geq 50$ and $<65$ years } & \multicolumn{2}{|l|}{$\geq 65$ years } \\
\hline & $\begin{array}{l}\text { Placebo } \\
(n=254)\end{array}$ & $\begin{array}{l}\text { Baricitinib } \\
4 \mathrm{mg}(\mathrm{n}=259)\end{array}$ & $\begin{array}{l}\text { Placebo } \\
(n=349)\end{array}$ & $\begin{array}{l}\text { Baricitinib } \\
4 \mathrm{mg}(\mathrm{n}=319)\end{array}$ & $\begin{array}{l}\text { Placebo } \\
(n=113)\end{array}$ & $\begin{array}{l}\text { Baricitinib } \\
4 \mathrm{mg}(\mathrm{n}=136)\end{array}$ \\
\hline Patients with $\geq 1$ adverse event & $212(83.5)$ & $229(88.4)$ & $326(93.4)$ & $296(92.8)$ & $111(98.2)$ & 135 (99.3) \\
\hline $\begin{array}{l}\text { Discontinuation from study due to } \\
\text { adverse event or death* }\end{array}$ & $6(2.4)$ & $6(2.3)$ & $14(4.0)$ & $18(5.6)$ & $7(6.2)$ & $12(8.8)$ \\
\hline $\begin{array}{l}\text { Discontinuation from study for any } \\
\text { reason }\end{array}$ & $21(8.3)$ & $14(5.4)$ & $31(8.9)$ & $28(8.8)$ & $19(6.8)$ & $17(12.5)$ \\
\hline Death† & 0 & 0 & $2(0.6)$ & $1(0.3)$ & 0 & $1(0.7)$ \\
\hline Serious adverse event $\ddagger$ & $10(3.9)$ & $8(3.1)$ & $11(3.2)$ & $15(4.7)$ & $12(10.6)$ & $12(8.8)$ \\
\hline Serious infections & $4(1.6)$ & $3(1.2)$ & $5(1.4)$ & $2(0.6)$ & $2(1.8)$ & $4(2.9)$ \\
\hline Cardiac disorders & $1(0.4)$ & 0 & $1(0.3)$ & $2(0.6)$ & $2(1.8)$ & $2(1.5)$ \\
\hline Patients with $\geq 1$ infection & $89(35.0)$ & 99 (38.2) & $86(24.6)$ & $125(39.2)$ & 38 (33.6) & $48(35.3)$ \\
\hline Herpes zoster & 0 & $2(0.8)$ & $2(0.6)$ & 5 (1.6) & 0 & $3(2.2)$ \\
\hline
\end{tabular}

Data presented as $\mathrm{n}(\%)$.

${ }^{*}$ A listing of the adverse events that led to discontinuation and a listing of serious adverse events can be found in online supplementary material.

†Deaths in placebo $\geq 50$ and $<65$ years due to subarachnoid haemorrhage and renal failure, baricitinib $4 \mathrm{mg} \geq 50$ and $<65$ years due to circulatory failure, and in baricitinib $4 \mathrm{mg} \geq 65$ years due to pneumonia.

¥Any serious adverse event based on the MedDRA dictionary system organ class.

regardless of whether treated with baricitinib or placebo. There were numerically more discontinuations due to AEs and herpes zoster in the baricitinib-treated patients versus placebo-treated patients; there were numerically more SAEs in the baricitinib-treated patients aged $\geq 50$ and $<65$ years and serious infections in the baricitinib-treated patients $\geq 65$ years. At 24 weeks, there were four deaths (all in patients $\geq 50$ years of age) (table 2). There was one SAE of hospitalisation due to thrombophlebitis (baricitinib $4 \mathrm{mg}<50$ ) and six due to fractures, all related to falls $(<50$ years: placebo $\mathrm{n}=1(0.4 \%)$, baricitinib $4 \mathrm{mg} \mathrm{n}=1(0.4 \%) ; \geq 50$ and $<65$ years: baricitinib $4 \mathrm{mg}$ $\mathrm{n}=2(0.6 \%)$; $\geq 65$ years: placebo $\mathrm{n}=1(0.9 \%)$, baricitinib $4 \mathrm{mg} \mathrm{n}=1(0.7 \%))$. None of these patients discontinued the study and all events resolved.

\section{DISCUSSION}

This post hoc analysis of two phase III studies of baricitinib $4 \mathrm{mg}$ in csDMARD-IR patients with RA demonstrated similar efficacy in each age group when assessing clinical parameters. With respect to safety, there was a higher percentage of patients in the older age group reporting AEs, SAEs and serious infections with numerically more events occurring with baricitinib. Rates were higher in the elderly group who discontinued medication secondary to an AE or death or who developed an SAE. Of note, the incidence of serious infections, although similar in the younger age groups, was higher in baricitinib versus placebo patients aged $\geq 65$ years.

Analysis of RA treatment in elderly patients has provided mixed results regarding efficacy and safety. Studies of TNF inhibitors have shown both reduced improvement in disease activity in elderly patients compared with younger patients ${ }^{12}$ as well as similar efficacy outcomes across age groups ${ }^{13}$ with similar rates of drug discontinuation in all age groups. ${ }^{12}{ }^{13}$ Similar to the current study, analyses of clinical trials of etanercept ${ }^{14}$ and tofacitinib, a JAK inhibitor, ${ }^{15}$ showed similar efficacy in older and younger patients, but an increased incidence of AEs, including discontinuation of treatment, in the older age groups. ${ }^{14} 15$ In contrast, an analysis assessing tocilizumab showed that elderly patients less often reached remission or good EULAR (European League Against Rheumatism) response compared with the younger patients, but drug maintenance and rates of $\mathrm{AE}$ leading to discontinuation were similar between the age groups. ${ }^{16}$

This study has some limitations. We did not include data on patients who received baricitinib $2 \mathrm{mg}$, which was evaluated in two trials in the baricitinib phase III development programme. This analysis was focused on csDMARD-IR patients, the patient populations of RA-BEAM and RA-BUILD. RA-BEAM, while the larger trial, contributing $76 \%$ of the baricitinib patients aged $\geq 65$ years, did not include a $2 \mathrm{mg}$ dose. RA-BUILD did include baricitinib $2 \mathrm{mg}$, but only 33 patients aged $\geq 65$ years received this dose. RA-BEACON, the other phase III trial that included baricitinib $2 \mathrm{mg}$, enrolled patients who were TNFi-IR. These patients who, on average, were older, with longer RA disease duration, more extensive treatment experience and demonstrated refractoriness are dissimilar from the patients enrolled in RA-BEAM and RA-BUILD. In RA-BEACON, 35 patients aged $\geq 65$ years received the $2 \mathrm{mg}$ dose. Based on the different characteristics of patients enrolled in the two studies with baricitinib $2 \mathrm{mg}$, different efficacy responses are expected for csDMARD-IR versus bDMARD-IR patients. Therefore, 
we do not believe it is appropriate to combine the populations from RA-BUILD and RA-BEACON for analysis. Additionally, the number of patients aged $\geq 65$ years who received baricitinib $2 \mathrm{mg}$ in each study is too small to support a single-study analysis. We did not include data from patients who received adalimumab in RA-BEAM because of the small size of the subgroup of patients aged $\geq 65$ years (adalimumab $\mathrm{n}=56$ ) and because sideby-side presentation of data would invite inappropriate comparison of pooled and single-study data. The clinical trial data reported here may not be representative of patients in clinical settings due to eligibility criteria of the trials. A minority of these elderly patients could be categorised as 'elderly-onset' and we did not subset the data accordingly. Finally, the observation period is short, especially for the placebo group, limiting the controlled-period assessment of safety.

In light of the literature available for bDMARDs and the data presented here, which reveal similar efficacy of baricitinib in elderly and younger patients and incidence of SAEs or withdrawal due to AEs in baricitinib-treated patients that were similar to age-matched placebo, age is not a contraindication to targeted therapies, including baricitinib. Nevertheless, given their comorbidities and potential for altered pharmacodynamics, elderly patients with RA should be followed with particular care.

Acknowledgements The authors thank Kathy Oneacre, MA, for medical writing support and assistance with preparation and submission of this manuscript.

Contributors RF contributed to the conception and design of the study, and acquisition, analysis and interpretation of data, and was involved with drafting and critical revision of the manuscript for important intellectual content. JA contributed to the conception, design and interpretation of data for the study and was involved with critical revision of the manuscript for important intellectual content. DM and JSS contributed to the conception and interpretation of data for the study and were involved with critical revision of the manuscript for important intellectual content. DES contributed to the interpretation of data for the study and was involved with critical revision of the manuscript for important intellectual content. JB contributed to the conception, design, and analysis and interpretation of data for the study and was involved with drafting and critical revision of the manuscript for important intellectual content. VA contributed to the acquisition, analysis and interpretation of data for the study and was involved with drafting of the manuscript.

Funding This study was funded by Eli Lilly and Company and Incyte.

Competing interests RF has received grant support, personal fees and nonfinancial support from Eli Lilly and Company, grant support and personal fees from Pfizer, AbbVie, Amgen, BMS, Genetech, and Novartis, and grant support from UCB, Roche and Sanofi-Genzyme; JA, VA, JB, DES and DM are full-time employees and stockholders of Eli Lilly and Company; JSS has received grant support and personal fees from Eli Lilly and Company, AbbVie, and Roche, and personal fees from Amgen, Astra-Zeneca, Astro, BMS, Celgene, Celltrion, Chugai, Gilead, Glaxo, ILTO0, Janssen, Medimmune, MSD, Novartis-Sandoz, Pfizer, Samsung, Sanofi and UCB.

Patient consent Obtained.

Ethics approval The studies were approved by each centre's institutional review board or ethics committee.
Provenance and peer review Not commissioned; externally peer reviewed.

Data sharing statement There are no additional data available.

Open Access This is an Open Access article distributed in accordance with the Creative Commons Attribution Non Commercial (CC BY-NC 4.0) license, which permits others to distribute, remix, adapt, build upon this work non-commercially, and license their derivative works on different terms, provided the original work is properly cited and the use is non-commercial. See: http://creativecommons.org/ licenses/by-nc/4.0/

(C) Article author(s) (or their employer(s) unless otherwise stated in the text of the article) 2017. All rights reserved. No commercial use is permitted unless otherwise expressly granted.

\section{REFERENCES}

1. Migliore $A$, Bizzi $E$, Laganà $B$, et al. The safety of anti-TNF agents in the elderly. Int J Immunopathol Pharmacol 2009;22:415-26.

2. Radovits BJ, Kievit W, Laan RF. Tumour necrosis factor-alpha antagonists in the management of rheumatoid arthritis in the elderly: a review of their efficacy and safety. Drugs Aging 2009;26:647-64.

3. Köller MD, Aletaha D, Funovits J, et al. Response of elderly patients with rheumatoid arthritis to methotrexate or TNF inhibitors compared with younger patients. Rheumatology 2009;48:1575-80.

4. Murota A, Kaneko Y, Yamaoka K, et al. Safety of biologic agents in elderly patients with rheumatoid arthritis. J Rheumatol 2016;43:1984-8.

5. Fleischmann R, Baumgartner SW, Weisman $\mathrm{MH}$, et al. Long term safety of etanercept in elderly subjects with rheumatic diseases. Ann Rheum Dis 2006;65:379-84.

6. Schmajuk G, Schneeweiss S, Katz JN, et al. Treatment of older adult patients diagnosed with rheumatoid arthritis: improved but not optimal. Arthritis Rheum 2007;57:928-34.

7. Fridman JS, Scherle PA, Collins R, et al. Selective inhibition of JAK1 and JAK2 is efficacious in rodent models of arthritis: preclinical characterization of INCB028050. J Immunol 2010:184:5298-307.

8. Genovese MC, Kremer J, Zamani O, et al. Baricitinib in patients with refractory rheumatoid arthritis. N Engl J Med 2016;374:1243-52.

9. Dougados $M$, van der Heijde D, Chen YC, et al. Baricitinib in patients with inadequate response or intolerance to conventional synthetic DMARDs: results from the RA-BUILD study. Ann Rheum Dis 2017;76:88-95

10. Taylor PC, Keystone EC, van der Heijde D, et al. Baricitinib versus Placebo or Adalimumab in Rheumatoid Arthritis. N Engl J Med Overseas Ed 2017;376:652-62.

11. Fleischmann R, Schiff M, van der Heijde D, et al. Baricitinib, methotrexate, or combination in patients with rheumatoid arthritis and no or limited prior disease-modifying antirheumatic drug treatment. Arthritis Rheumatol 2017;69:506-17.

12. Radovits BJ, Kievit W, Fransen J, et al. Influence of age on the outcome of antitumour necrosis factor alpha therapy in rheumatoid arthritis. Ann Rheum Dis 2009;68:1470-3.

13. Genevay S, Finckh A, Ciurea A, et al. Tolerance and effectiveness of anti-tumor necrosis factor alpha therapies in elderly patients with rheumatoid arthritis: a population-based cohort study. Arthritis Rheum 2007;57:679-85

14. Fleischmann R, lqbal I. Risk: benefit profile of etanercept in elderly patients with rheumatoid arthritis, ankylosing spondylitis or psoriatic arthritis. Drugs Aging 2007;24:239-54.

15. Curtis JR, Schulze-Koops H, Takiya L, et al. Efficacy and safety of tofacitinib in older and younger patients with rheumatoid arthritis. Clin Exp Rheumatol 2017;35:390-400.

16. Pers YM, Schaub $R$, Constant $E$, et al. Efficacy and safety of tocilizumab in elderly patients with rheumatoid arthritis. Joint Bone Spine 2015;82:25-30. 